\title{
Fabrication puts suspects at risk: blindness to changes in transgression-related statements
}

Citation for published version (APA):

Sauerland, M., Schell - Leugers, J., \& Sagana, A. (2015). Fabrication puts suspects at risk: blindness to changes in transgression-related statements. Applied Cognitive Psychology, 29(4), 544-551.

https://doi.org/10.1002/acp.3133

Document status and date:

Published: 01/01/2015

DOI:

10.1002/acp.3133

Document Version:

Publisher's PDF, also known as Version of record

Document license:

Taverne

Please check the document version of this publication:

- A submitted manuscript is the version of the article upon submission and before peer-review. There can be important differences between the submitted version and the official published version of record.

People interested in the research are advised to contact the author for the final version of the publication, or visit the DOI to the publisher's website.

- The final author version and the galley proof are versions of the publication after peer review.

- The final published version features the final layout of the paper including the volume, issue and page numbers.

Link to publication

\footnotetext{
General rights rights.

- You may freely distribute the URL identifying the publication in the public portal. please follow below link for the End User Agreement:

www.umlib.nl/taverne-license

Take down policy

If you believe that this document breaches copyright please contact us at:

repository@maastrichtuniversity.nl

providing details and we will investigate your claim.
}

Copyright and moral rights for the publications made accessible in the public portal are retained by the authors and/or other copyright owners and it is a condition of accessing publications that users recognise and abide by the legal requirements associated with these

- Users may download and print one copy of any publication from the public portal for the purpose of private study or research.

- You may not further distribute the material or use it for any profit-making activity or commercial gain

If the publication is distributed under the terms of Article $25 \mathrm{fa}$ of the Dutch Copyright Act, indicated by the "Taverne" license above, 


\title{
Fabrication Puts Suspects at Risk: Blindness to Changes in Transgression-related Statements
}

\author{
MELANIE SAUERLAND ${ }^{1 *}$, JENNIFER MARIA SCHELL-LEUGERS $^{2}$ and ANNA SAGANA ${ }^{1}$ \\ ${ }^{1}$ Department of Clinical Psychological Science, Maastricht University, Maastricht, The Netherlands \\ ${ }^{2}$ University College Maastricht, Maastricht, The Netherlands
}

\begin{abstract}
Summary: Based on the finding that deceptive and misleading interrogation techniques are not uncommon, we investigated to what extent participants may be blind to alterations introduced to their accounts of past transgressions. Drawing from the source-monitoring framework, we hypothesized that participants' truthfulness and whether they had committed a transgression in the past (transgression history) would be predictive of blindness. When filling out a questionnaire about their past transgressions, 80 participants fabricated some of their answers. Prior to an interview 1 week later, two previously fabricated and two truthful answers were covertly altered by the experimenter. We found substantial blindness rates, and, as hypothesized, blindness was more pronounced for (1) fabricated than truthful responses and (2) alterations with transgression history compared with no transgression history. Possible consequences may include the creation of guilt presumption and increasing pressure to obtain a confession. Both can be hazardous for suspects and the legal decision-making process. Copyright (C) 2015 John Wiley \& Sons, Ltd.
\end{abstract}

It is not uncommon for people to resort to a white lie in an attempt to conceal unfavorable details of a story or a situation that went out of hand. For instance, when fabrication is a deliberate and conscious act, it is reasonable to assume that they would notice alterations in their statements that are introduced by external sources. The recent introduction of blindness phenomena, however, contests this view. This research shows that people do not necessarily notice alterations that are covertly made to their deliberate choices, preferences, or intentional statements. The evidence also suggests that individuals may even provide motivational arguments in support of such decisions that they in fact did not make (Johansson, Hall, \& Sikström, 2008).

The typical blindness paradigm consists of three phases. In the first phase, participants indicate a preference, provide a frequency or intensity judgment, or make an objective decision (e.g., Which of the two voices do you prefer? How often do you suffer from symptom $x$ ? Who of these six people did you see committing the crime, if any?). In phase 2, participants are presented either with their own response (unaltered trial) or with a response that is inconsistent with their own (altered trial). They are then asked to explain their answer. In phase 3, a posttest questionnaire or interview is administered in which participants are informed about the possibility that some of their answers were altered, and are asked to indicate if this was the case for them. Typically, only few of the altered trials are detected concurrently (in phase 2), suggesting that many participants accept the altered answer as their own (i.e., they are blind to the alteration). Retrospective detection, which occurs in phase 3, is typically higher, although blindness can still be considerable at this stage.

The first studies investigating blindness phenomena explicitly addressed blindness to one's choices (i.e., choice blindness), covering domains as diverse as moral, consumer, and voter decision-making (Hall, Johansson, \& Strandberg, 2012; Hall, Johansson, Tärning, Sikström, \& Deutgen,

*Correspondence to: Melanie Sauerland, Section Forensic Psychology, Faculty of Psychology and Neuroscience, Department of Clinical Psychological Science, Maastricht University, PO Box 616, Maastricht 6200 MD, The Netherlands. E-mail: melanie.sauerland@maastrichtuniversity.nl
2010; Hall et al., 2013), and preferential choices referring to faces, voices, and other visual stimuli (Johansson, Hall, Sikström, \& Olsson, 2005; Sauerland, Sagana, \& Otgaar, 2013; Sauerland, Sagana, Otgaar, \& Broers, 2014). Recently, the concept has been expanded to symptom evaluations (Merckelbach, Jelicic, \& Pieters, 2011a, 2011b) and objective decisions, including attributions of facial identity (Sauerland, Sagana, Siegmann, Merckelbach, \& Jenkins, 2014) and eyewitness identification decisions (Sagana, Sauerland, \& Merckelbach, 2013, 2014). Although the proportion of blind participants varies naturally across experiments, all studies found a meaningful number of participants to be blind, both concurrently and retrospectively.

Recently, Sauerland et al. (2013) investigated participants' blindness to alterations of self-reports on their history of norm-violating behaviors. Across two experiments, participants were asked to indicate how frequently they had committed each of 18 norm-violating behaviors on a 4-point scale ranging from never to often. After 10 minutes (experiment 1) or 1 week (experiment 2), participants answered questions about four of their responses. Before the interview, the experimenter altered two answers by increasing or decreasing them by two scale points. For example, if participants had indicated that they had seldom stolen a bike, they were now confronted with a question like: 'You answered that you have often stolen a bike. Could you tell us about these incidents?' Across conditions between $8 \%$ and $37 \%$ of the alterations remained unreported. In line with earlier findings (Johansson, Hall, Tärning, Sikström, \& Chater, 2013; Merckelbach et al., 2011a), long-term effects emerged at a 4 -week follow-up of experiment 2 . When completing the questionnaire again, some participants shifted their answers in comparison to the answer they had given earlier for altered items, although not always in the manipulated direction. On the other hand, not a single shift occurred for unaltered items. Similar findings have been reported in studies investigating participants' reaction to the insertion of wrongful details into their interrogation protocols concerning a witnessed robbery. Blindness rates varied from $40 \%$ to $90 \%$, depending on the experimental condition (Christianson, Engelberg, \& 
Gustafson, 2007; experiment 2; van Bergen, Horselenberg, Merckelbach, Jelicic, \& Beckers, 2010). Possible consequences of this failure to detect wrongful details in one's witness testimony may include the wrongful reconstruction of the crime, leading the investigation to a dead end or an innocent suspect.

The current study sought to extend Sauerland et al.'s (2013) study by investigating two moderators that we expected to amplify the risk for blindness by disrupting the ability to accurately attribute the source of a memory (i.e., source monitoring; Johnson, Hashtroudi, \& Lindsay, 1993): participants' truthfulness (truthful versus fabricated response) and previous engagement in a specific transgression (transgression history: yes versus no). We selected these moderators because they can be relevant for investigating crimes. First, in an attempt to increase their credibility, both innocent and guilty suspects may choose to fabricate parts of their testimony. This could be because they may fear being disbelieved (Vrij, Granhag, Mann, \& Leal, 2011) or because the truth may appear overly incriminating (Allison, Mathews, \& Michael, 2012). Second, individuals with a criminal record (i.e., transgression history) have a higher chance to become suspects, because they may be known to the police or their details may appear based on information entered into the criminal database. Additionally, their (arrest) photographs are more likely to appear in mug shot photo albums, which are presented to witnesses and victims to crimes at the police station in an attempt to narrow down on the identity or appearance of the perpetrator. Consequently, they are more likely to be interrogated.

According to the source-monitoring framework (Johnson, Raye, Foley, \& Foley, 1981; Johnson et al., 1993), people resort to memory characteristics when deciding about the source of a memory. Source discrimination can concern different internal (what one imagined versus what one dreamt) or external sources (what my brother said versus what my father said), or internal versus external sources (what I dreamt versus what happened in reality). The different memory characteristics include records of sensory information (e.g., sound or color), contextual information (spatial or temporal), semantic detail, affective information (e.g., emotions), and cognitive operations (e.g., reasoning, thought, and imagery processes). Memories of imagined events are associated with more cognitive operations than memories that originate in perception. On the other hand, memories that originate in perception are characterized by more perceptual, contextual, semantic, and affective information, compared with imagined events. As the accuracy of the sourcemonitoring process is, among other factors, determined by the type and the amount of memory characteristics associated with a memory, source confusion can be caused by increasing the number of cognitive operations to the memory record (Johnson et al., 1993).

In the current study, participants indicated how often they had committed each of 24 transgressions in the past. For some questions, participants were instructed to answer truthfully, while for others, the instruction was to fabricate an answer. The act of fabricating an answer should increase the amount of cognitive operation entries for the referring memory, compared with items for which a truthful answer was given. Prior to an interview 1 week later, the experimenter altered some of the participant's answers, including both truthful and fabricated responses. When interviewed about their responses, participants should still be able to retrieve the truthful answers from autobiographical memory and note a discrepancy between the truthful answer and the answer stated by the experimenter. However, for the fabricated items, the association of the memory with cognitive operations should make it more difficult for participants to decide whether the identified discrepancy from the truth was generated by themselves (i.e., by following the instruction to fabricate) or whether the discrepancy might be caused by another source (e.g., by an error made by the experimenter or oneself). Therefore, ruling out external sources should be easier for truthful responses, compared with fabricated ones. Accordingly, we expected lower detection rates for alterations of fabricated than truthful answers.

Another assumption within the framework is that, when uncertain about the source of a memory, the feeling of familiarity associated with an event is used as an indicator of its actual occurrence (Johnson et al., 1993; Polage, 2012). Alterations that cause discrepancies in participants' feeling of familiarity should therefore be detected with more ease than alterations that do not cause such discrepancies. Consequently, blindness rates for alterations that refer to transgressions that participants previously did not engage in (no transgression history) should be lower than blindness rates for transgressions that participants did engage in at least once before (transgression history). In the current study, changing a no transgression history response to a transgression history response entails a larger shift in familiarity than increasing or decreasing one history response to a different history response. ${ }^{1}$ First support for this idea comes from previous research showing increased blindness rates for higher rather than lower symptom ratings (Merckelbach et al., 2011a, 2011b) and higher rather than lower scores on the Questionnaire about History of Norm-Violating Behaviors (Sauerland et al., 2013). To recap, drawing from the source-monitoring framework and earlier findings, we hypothesize that a suspect with transgression history is more likely to be blind to alterations. At the same time, having a transgression history increases the probability of a suspect to appear in mug shots and hence to be interrogated. This may include procedures using deceitful techniques. Combined, these mechanisms leave suspects with a transgression history (1) at a greater risk of being exposed to an interrogation situation and (2) of being deceived in an interrogation situation, compared with suspects without transgression history (i.e., criminal record).

\section{METHOD}

\section{Participants}

Eighty participants took part in the experiment $(25$ men and 55 women; mean $[M]_{\text {age }}=22.1$ years, standard deviation $[S D]_{\text {age }}=2.8$, age range: $18-38$ years $)$. They were bachelor

\footnotetext{
${ }^{1}$ Alterations of transgression history answers to no-history answers were not performed in the current study.
} 
(81.3\%) and master students $(11.3 \%)$ of different faculties, most of which at the Faculty of Psychology and Neuroscience $(67.5 \%)$. Six participants were nonstudents. They received course credits or a gift certificate for their participation. The study was approved by the standing ethical board of the faculty.

\section{Design}

A 2 (fabrication: yes versus no) $\times 2$ (transgression history: yes versus no) $\times 2$ (transgression severity: high versus low) mixed design was employed. Fabrication was manipulated by means of instruction, that is, participants were instructed to respond truthfully or fabricate an answer. Two fabricated and two truthful responses were altered for each participant (i.e., within-subjects factor). Participants' answers provided in the Questionnaire about History of Norm-Violating Behaviors were used to assess transgression history. Never answers were coded as 0 , and answers between one time and nine times or more were coded as 1 . Additionally, we counterbalanced transgression severity (high versus low; cf. section on Materials).

Concurrent and retrospective detection served as dependent variables. Detections that occurred during the interview were termed concurrent detection and detections indicated in the post-interview questionnaire retrospective detection.

\section{Materials}

\section{Twenty-four-item Questionnaire about History of} Norm-Violating Behaviors

This questionnaire consisted of 24 items concerning normviolating behaviors. Eighteen items were taken from Sauerland et al. (2013), and we added six more. Apart from using 24 rather than 18 items, the present version of the Questionnaire about History of Norm-Violating Behaviors also differed in terms of the employed rating scale from the questionnaire used by Sauerland et al. Specifically, participants were asked to indicate how many times they had engaged in each behavior described by the item on a 10-point scale $(0=$ zero times, $1=$ once, $\ldots, 9=$ nine times or more $)$. We did this to decrease the vagueness of the scale. For example, there is no standard for how many times seldom stands for. By asking participants to make more precise indications, we would be able to discuss a number of specific occasions during which the participants showed the transgressive behavior. Using the eight different versions of the questionnaire, the position of the fabricated items position (positions 11 and 13 versus 18 and 20) and the order of the four questioned items (ABCD, CDAB, BADC, or DCBA) were counterbalanced across participants. Table 1 gives an overview of the questionnaire and its structure.

The cover page of the 24-item Questionnaire about History of Norm-Violating Behaviors provided participants with the following written instructions:

For the following questions, please indicate how many times you have shown the following behavior. Please answer all questions truthfully. There is an exception, however: We would like to ask you to lie to questions 11,12 , and 13 [18, 19, and 20].
Participants were then provided with an example of a truthful and an untruthful answer. For the untruthful items, participants were asked to respond with an untruthful value that fell within the 3-8 range on the scale. This range was chosen to ensure that the experimenter would be able to increase or decrease the score by three scale points. No explanation was given as to why participants should lie in response to some of the questions. If participants had any questions, they could now turn to the experimenter. A few participants made use of this opportunity, and the experimenter then repeated the instructions in only female experimenters her own words.

The first page of questions was preceded by the sentence Please answer the following questions truthfully. When participants reached item 11 (18), a new instruction read Please lie on the following three questions. Following the three untruthful items, the final instruction read Please answer all remaining questions truthfully.

After responding to all questions, participants were asked whether they had actually fabricated their answers for the referring items. If the answer was to the negative, the instructions prompted them to go back to these questions and give an untruthful answer, as indicated by the instructions. This instruction served as a manipulation check to ensure that the responses on those items were actually untruthful. Only very few participants had to go back to change their answer because they had not lied initially. Furthermore, participants had to signify whether their indicated value represented an increase or decrease of the true value and by how many scale points it diverted from it. From this information, we inferred the true frequencies with which participants had performed the referring transgressions and derived their transgression history.

\section{Selection of alteration items}

The same four items were selected to be altered for all participants. Although not central to our primary research question, we counterbalanced transgression severity across fabrication conditions. This was based on the assumption that high-severity transgressions may be more distinct and more stressful to commit than low-severity transgressions, both of which have been found to enhance encoding (Dodson \& Schacter, 2001; LaBar \& Cabeza, 2006; McDonough \& Gallo, 2008; Roozendaal \& McGaugh, 2011). Accordingly, blindness rates may be higher for lowseverity compared with high-severity transgressions. We controlled for transgression severity by selecting two items that scored high and two that scored low on severity, as established based on Sauerland et al.'s (2013) pilot data. The means refer to the ratings on a 5-point (1-5) scale. The specific items were A. bought a stolen bike (low severity: $M=3.27 ; S D=0.96)$, B. committed small-scale shoplifting (high severity: $M=4.53 ; S D=0.52$ ), C. used disabled parking space (low severity: $M=3.47$; $S D=0.99$ ), and D. destroyed public or other people's property (high severity; $M=4.60 ; S D=0.51)$. These items were selected to differ across $(t \mathrm{~s}(14) \geq 4.68, p \mathrm{~s} \leq .001)$ but not within severity level (within high severity: $t(14)=1.00, p=.334$; low severity: $t(14)=0.68, p=.510)$. 
Table 1. Overview of Questionnaire about History of Norm-Violating Behaviors, including questioned items, altered items, and severity of altered items as well as descriptives for each of the 24 items

\begin{tabular}{|c|c|c|c|c|c|c|c|c|}
\hline Item & & $\begin{array}{l}\text { Questioned } \\
\text { items }\end{array}$ & $\begin{array}{c}\text { Altered } \\
\text { items }\end{array}$ & $\begin{array}{l}\text { Transgression } \\
\text { severity }\end{array}$ & $M$ & $S D$ & Min & Max \\
\hline 1 & Rode through red traffic light & & & & 3.21 & 3.15 & 0 & 9 \\
\hline 2 & $\begin{array}{l}\text { "Borrowed" DVD from house mate } \\
\text { without asking }\end{array}$ & $X$ & & & 0.85 & 1.79 & 0 & 9 \\
\hline 3 & $\begin{array}{l}\text { Walked by blind date without } \\
\text { disclosing identity }\end{array}$ & & & & 0.13 & 0.43 & 0 & 2 \\
\hline 4 & Deflated bicycle tire & $\mathrm{X}$ & & & 0.40 & 0.88 & 0 & 4 \\
\hline 5 & Tortured bug & & & & 2.64 & 3.18 & 0 & 9 \\
\hline 6 & Stole a bike & $\mathrm{X}$ & & & 0.64 & 1.40 & 0 & 6 \\
\hline 7 & $\begin{array}{l}\text { Drove away from accident in which } \\
\text { I was involved }\end{array}$ & $X$ & & & 0.23 & 0.71 & 0 & 5 \\
\hline 8 & Was in trouble with the police & & & & 0.73 & 1.09 & 0 & 5 \\
\hline 9 & Sprayed graffiti illegally on a wall & & & & 0.38 & 1.12 & 0 & 6 \\
\hline 10 & Left junk in the park after picnic & & & & 1.95 & 2.47 & 0 & 9 \\
\hline 11 & Bought a stolen bike ${ }^{\mathrm{a}}$ & $\mathrm{X}$ & $\mathrm{X}$ & Low & $\begin{array}{c}0.67 \\
(5.35)\end{array}$ & $\begin{array}{c}1.28 \\
(1.73)\end{array}$ & $\begin{array}{c}0 \\
(3)\end{array}$ & $5(8)$ \\
\hline 12 & $\begin{array}{l}\text { Used public transportation } \\
\text { without ticket }\end{array}$ & $X$ & & & $\begin{array}{c}4.95 \\
(4.98)\end{array}$ & $\begin{array}{c}3.31 \\
(1.95)\end{array}$ & $\begin{array}{c}0 \\
(3)\end{array}$ & $9(8)$ \\
\hline 13 & Committed small-scale shoplifting ${ }^{\mathrm{a}}$ & $\mathrm{X}$ & $\mathrm{X}$ & High & $\begin{array}{c}2.08 \\
(5.21)\end{array}$ & $\begin{array}{c}2.91 \\
(1.53)\end{array}$ & (3) & $9(8)$ \\
\hline 14 & $\begin{array}{l}\text { Kept silent about too much change } \\
\text { in supermarket }\end{array}$ & & & & 2.30 & 1.98 & 0 & 9 \\
\hline 15 & Sent hate mail to ex girl-/boy-friend & & & & 0.58 & 1.27 & 0 & 6 \\
\hline 16 & Cheated my insurance & & & & 0.58 & 1.28 & 0 & 9 \\
\hline 17 & $\begin{array}{l}\text { Used physical violence against others } \\
\text { in conflict }\end{array}$ & & & & 1.64 & 2.29 & 0 & 9 \\
\hline 18 & $\begin{array}{l}\text { Used parking space for people } \\
\text { with disabilities }\end{array}$ & $X$ & $X$ & Low & $\begin{array}{c}0.76 \\
(5.00)\end{array}$ & $\begin{array}{l}1.67 \\
(1.84)\end{array}$ & $\begin{array}{c}0 \\
(3)\end{array}$ & $9(8)$ \\
\hline 19 & Stole towel from a hotel I stayed in & & & & $\begin{array}{l}1.23 \\
(5.00)\end{array}$ & $\begin{array}{l}1.33 \\
(1.78)\end{array}$ & $\begin{array}{l}0 \\
(3)\end{array}$ & $4(8)$ \\
\hline 20 & $\begin{array}{l}\text { Destroyed public or other people's } \\
\text { property (bike, phone box, bus } \\
\text { shelter) }\end{array}$ & $\mathrm{X}$ & $\mathrm{X}$ & High & $\begin{array}{c}0.88 \\
(5.21)\end{array}$ & $\begin{array}{c}1.47 \\
(2.00)\end{array}$ & $\begin{array}{c}0 \\
(3)\end{array}$ & $6(8)$ \\
\hline 21 & Stole money from my parents' purse & & & & 1.43 & 2.24 & 0 & 9 \\
\hline 22 & Scratched a car & & & & 0.63 & 0.91 & 0 & 4 \\
\hline 23 & $\begin{array}{l}\text { Stole kitchen utensils from } \\
\text { student cafeteria }\end{array}$ & & & & 0.68 & 1.40 & 0 & 7 \\
\hline 24 & Cheated in high school exam & & & & 4.90 & 3.38 & 0 & 9 \\
\hline
\end{tabular}

Note: $S D$, standard deviation; $M$, mean.

${ }^{a}$ The position of the items that are displayed on positions 11, 13, 18, and 20 and whether participants were asked to fabricate or be truthful were counterbalanced. Descriptives refer to a 10-point scale ranging from 0 to 9 . Descriptives in parentheses refer to fabrication condition.

\section{Posttest questionnaire}

In the posttest questionnaire, participants were first asked whether they had noticed anything strange during the experiment, then whether they had noticed anything odd with the answers to the 24-item Questionnaire about History of Norm-Violating Behaviors. Next, participants were (incorrectly) told that there were two conditions they could have been assigned to with equal chance. In condition 1, the answers that they were presented with in session 2 were always the ones that they gave in session 1 . In condition 2 , some of the answers that were presented in session 2 were altered. Participants were asked to indicate which condition they thought they were in. If they thought they had been in condition 2, they were asked how many times they noticed a change for sure and how many times they found something odd. Finally, participants had to indicate which questions specifically they thought had been altered. For this last question, they were given the altered version of their filled-in questionnaire for reference. These answers were used as an indication of retrospective detection, that is, such detections that might have occurred, but were not reported by the participants during the interview.

\section{Procedure}

The experiment consisted of two sessions. In session 1, participants signed the informed consent form and completed the 24-item Questionnaire about History of Norm-Violating Behaviors. In session 2, which took place 1 week later, participants were interviewed about nine of their answers on the questionnaire. Prior to the interview, the experimenter altered the answers to four questions (bought a stolen bike, used disabled parking space, committed small-scale shoplifting, and destroyed public or other people's property) by three full scale points. In principle, the scores were increased, unless this was not possible (i.e., if participants had endorsed a score of 7 or higher). In that case, they were decreased. That occurred in 50 of the 320 alterations 
(15.6\%). Preliminary analyses showed that the direction of alteration had no effect on detection rates.

The questions covered in each interview concerned the four altered items (two previously fabricated by the participant and two answered truthfully) and five unaltered ones (of which one was fabricated). We selected nine items for the interview to allow for questions concerning several altered and unaltered items as fillers, but refrained from including all items in the interview to keep its duration at a moderate level (see Merckelbach et al., 2011a, 2011b; and Sauerland et al., 2013, for a similar approach). Table 1 shows an overview of the items the participants were questioned about as well as the descriptive statistics for all items. To avoid further complication of the already complex design and to minimize the burden on the experimenters (and to avoid experimenter errors), the order of questioning was always analogous to the sequence of the items in the questionnaire. Note, however, that across participants, eight different item sequences were implemented, as described in the Section on Twenty-four-item Questionnaire about History of Norm-Violating Behaviors.

Before the interview began, participants were explicitly informed about the confidential nature of the interview to put them at ease when talking about their past transgressions. Furthermore, experimenters were instructed to react purely interested and never judgmental upon participants' reports of past transgressions and to encourage participants in their report nonverbally (e.g., by nodding). Because the experimenters were not blind to the hypothesis that fabrication would foster blindness (but were blind to the second hypothesis), we took several measures to avoid experimenter bias. First, the specific questions that would be altered were predetermined by the randomized experimental testing plan. That is, experimenters could not choose to alter answers that they deemed more or less difficult to detect for the fabricated versus nonfabricated conditions. Second, experimenters followed a protocol during the interview, which they practiced in a training session with the first author. Experimenters were instructed to ask three or four questions about each of the nine interview items. The questions were designed to raise the impression that the experimenters were genuinely interested in participants' opinion about norm violations and their history of transgressions. Questions always began with a statement referring to the (alleged) answer the participant had given (i.e., 'You answered that you have parked in a disabled parking space five times. Could you tell me something about the circumstances?' or 'You answered that you have never parked on a disabled parking space. Why not?'). Subsequently, the experimenter might ask: 'Why do you think other people would park on a disabled parking space?'. Depending on participants' answers, follow-up questions were asked to be certain about whether or not the alteration had been discovered. Reactions to these questions were used to establish concurrent blindness or detection (e.g., doubtful facial expression, including evident hesitation and frowning as well as statements such as 'Did I really say this?' or 'I did not say this'). The experimenters discussed which kinds of instances should be recorded as detections and which should not with the first author prior to and during data collection, where necessary.
After the interview, participants filled out the posttest questionnaire, from which retrospective detection was derived. Last, participants were debriefed.

\section{RESULTS}

\section{Descriptives of transgression history and detection of alterations}

Of the 320 alterations performed in total, 16 observations were excluded from our analyses for the following reasons: (1) Participants made an error when indicating how many steps their truthful answer diverged from the one they had given in the posttest questionnaire such that computing the truthful answer would result in a value smaller than zero or larger than nine (four observations). (2) An altered response was identical with or very close to $( \pm 1)$ the true response for that item (eight observations). (3) A participant failed to follow the instructions and made an indication larger than 8 or smaller than 3 for the fabrication items (four observations).

Participants reported transgression history for 110 of the 304 remaining altered items, with an average of 1.4 items with a transgression history per participant. Twenty-eight participants reported no transgression history, 18 reported history for one item, 16 for two, 12 for three, and 6 participants for four items.

Of the 304 alterations, 107 (35.2\%) were detected concurrently. Detection for the four different items ranged from $31.1 \%$ to $39.2 \%$. Nineteen participants did not detect any alteration concurrently, and one participant detected all four. As for retrospective detection, there were 150 (49.3\%) detections, with a range of $40.5 \%$ to $59.5 \%$. Twenty-three participants detected no alteration retrospectively, and 13 participants detected all four.

Across the 400 trials in which participants were asked questions about answers that had not been altered, participants rejected these answers as incorrect on 12 occasions concurrently (nine participants once and one participant three times). Retrospectively, this number increased to 70 occasions. Most participants rejected one item $(n=21)$, but several rejected two $(n=6)$, three $(n=5)$, four $(n=3)$, or even all five items $(n=2)$. To test the idea that participants might be suspicious regardless of an alteration, we compared the proportion of detection in altered trials with the proportion of unfounded suspicion expressed in unaltered cases. Both, concurrently [altered: $M=35.2 \%, 95 \%$ confidence interval (CI) $[30.0,40.7]$; unaltered: $M=3.0 \%, 95 \%$ CI $[1.7,5.2]]$ and retrospectively (altered: $M=49.3 \%, 95 \%$ CI [43.8, 54.9]; unaltered: $M=17.5 \%, 95 \%$ CI [14.1, 21.5]), responses were rejected significantly more often in altered, compared with unaltered trials, as established using McNemar's test (concurrent detection: $p<.001$, odds ratio $=16.42,95 \%$ CI $[9.17,29.40]$; retrospective detection: $p<.001$, odds ratio $=2.14,95 \%$ CI $[1.77,2.59])$.

\section{Impact of fabrication, transgression history, and transgression severity on detection}

Because the inclusion of within-subjects factors produces correlated data, a standard ordinary least square regression 
analysis would not be a valid statistical model for the current design. Therefore, we performed generalized estimatingequation analyses using IBM SPSS Statistics 21 (IBM Corporation Armonk, New York, United States). The generalized estimating-equation model provides an appropriate alternative, as it accounts for the correlated residuals via the specification of a working correlation matrix (Hanley, Negassa, Edwardes, $\&$ Forrester, 2003). Our model included fabrication (yes versus no), transgression history (yes versus no), and transgression severity (high versus low). Concurrent and retrospective detection were the dependent variables. In the initial analyses, we included all main effects and two-way interactions in the equation. Next, we sequentially excluded nonsignificant two-way interactions. To code transgression history (yes versus no), answers to fabricated responses were recomputed based on the information provided by the participants on the direction and number of scale points their response diverted from the real value and were dichotomized. A true value of 0 was coded as no transgression history, and true value between 1 and 9 was coded as transgression history. Analyses were carried out twice, once including both increase and decrease alterations and once including only increases. Separate analyses looking at increases on the one side and decreases on the other side were not possible because of the relatively small number of decrease alterations in total. The results of these two parallel analyses (increases only versus increases and decreases) were analogous. In the succeeding text, we therefore report the analyses including both increases and decreases, including $304 \mathrm{ob}-$ servations. Additionally, we also ran all analyses replacing the dichotomous factor fabrication with deviation from truth (varying between 0 and 8). Again, the pattern of results was identical. In the following, we summarize the results of the analyses, while the statistics can be found in Tables 2 and 3 .

\section{Concurrent detection}

Table 2 shows that the final model for concurrent detection contained no interactions and the two main effects of fabrication and transgression history were significant. In this model, the intercept $(0.95)$ denotes the predicted level of concurrent detection given a participant who gave a response to a truthful item (fabrication $=0$ ), concerning a low severity transgression (severity $=0$ ) they did not commit in the past (transgression history $=0$ ). As expected, alterations were less likely to be detected when participants had fabricated their answer $(b=-2.63)$ and for items with transgression history $(b=-1.49)$. To summarize, concurrent detection rates were negatively affected by both fabrication and transgression history, as expected.

\section{Retrospective detection}

As shown in Table 3, the final model for retrospective detection resembled the one for concurrent detection and contained no interactions, while the two main effects of fabrication and transgression history were significant. Again, alterations were less likely to be detected when participants had fabricated their answer $(b=-0.63)$ and for items with transgression history $(b=-0.99)$. That is, just like concurrent detection, retrospective detection rates were negatively affected by both fabrication and transgression history, as expected.

\section{DISCUSSION}

The present study confirmed the earlier finding that blindness to alterations in self-reports on one's history of normviolating behaviors occurs at a substantial rate (Sauerland et al., 2013). Drawing from the source-monitoring framework (Johnson et al., 1981, 1993), we predicted that fabrication and transgression history should amplify blindness rates. The hypotheses were supported by the results. Higher blindness levels were found (1) for fabricated than truthful answers and (2) for transgressions that participants had committed in the past, rather than not. Based on the finding that distinctiveness and stress enhance encoding (Dodson \&

Table 2. Final GEE model for the predictive value of fabrication, transgression history, and transgression severity on concurrent detection

\begin{tabular}{lcccrrr}
\hline & $B$ coefficient & 95\% confidence interval & Standard error & Wald $\chi^{2}$ & df & $p$ \\
\hline Intercept $^{\mathrm{a}}$ & 0.95 & $0.45 ; 1.46$ & 0.26 & 13.92 & 1 & $<.001$ \\
Fabrication $_{\text {Transgression history }}$ & -2.63 & $-3.35 ;-1.91$ & 0.37 & 51.16 & 1 & $<.001$ \\
Transgression severity & -1.49 & $-2.16 ;-0.82$ & 0.34 & 19.00 & 1 & $<.001$ \\
\hline
\end{tabular}

Note: GEE, generalized estimating equation; df, degrees of freedom.

${ }^{\mathrm{a}}$ Intercept denotes the predicted level of concurrent detection, given a participant who gave a response to a truthful item (fabrication $=0$ ), concerning a low-severity transgression (severity $=0$ ) they did not commit in the past (transgression history $=0$ ).

Table 3. Final GEE model for the predictive value of fabrication, transgression history, and transgression severity on retrospective detection

\begin{tabular}{lcccrrr}
\hline & $B$ coefficient & $95 \%$ confidence interval & Standard error & Wald $\chi^{2}$ & df & $p$ \\
\hline Intercept $^{\mathrm{a}}$ & 0.68 & $0.23 ; 1.12$ & 0.23 & 8.81 & 1 & .003 \\
Fabrication $_{\text {Transgression history }}$ & -0.63 & $-1.11 ;-0.16$ & 0.24 & 6.82 & 1 & .009 \\
Transgression severity & -0.99 & $-1.43 ;-0.54$ & 0.23 & 18.84 & 1 & $<.001$ \\
\hline
\end{tabular}

Note: GEE, generalized estimating equation; df, degrees of freedom.

${ }^{\mathrm{a}}$ Intercept denotes the predicted level of retrospective detection, given a participant who gave a response to a truthful item (fabrication $=0$ ), concerning a low-severity transgression (severity $=0$ ) they did not commit in the past (transgression history $=0$ ). 
Schacter, 2001; LaBar \& Cabeza, 2006; McDonough \& Gallo, 2008; Roozendaal \& McGaugh, 2011), we explored the idea that blindness rates might be higher for low-severity transgressions. The current findings provide no support for this thought. This finding may be because our list of transgressions did not contain some of the more serious crimes. While blindness to alterations regarding serious crimes may be difficult to study in a student or community sample, it may be interesting to conduct a study in a prison. Another possible factor that may moderate the effect could be transgression prevalence.

The current findings are relevant for the implementation of suspect interrogations. In our experiment, the experimenter altered some participant answers prior to a second session. Analogously, in successive interviews, an interrogator may decide to alter some information provided by the suspect (Janardhanan, 2013; Ridolfi \& Possley, 2010) so that the statement becomes more incriminating as part of the investigative strategy. The two factors studied in the current experiment expose the particular vulnerability of suspects to blindness effects in such a situation: First, given the particular situation of a suspect, it is not unlikely that they fabricate at least part of their testimony-regardless of innocence-either out of fear to be disbelieved (Vrij et al., 2011) or because of the incriminating nature of the truth (Allison et al., 2012). Second, having a transgression history (i.e., a criminal record) makes source monitoring more difficult. Both of these conditions have been shown to increase the likelihood of being blind to changes in one's own report (the current study; Merckelbach et al., 2011a; Sauerland et al., 2013).

The possible consequences for the outcome of a police investigation may be hazardous for suspects and the legal decision-making process. Although studies have shown that inconsistencies are a natural part of truthful memories (Odinot, Wolters, \& van Giezen, 2013; Oeberst, 2012; Smeets, Candel, \& Merckelbach, 2004), inconsistencies are commonly viewed to be an indicator of deception (Berman \& Cutler, 1996; Brewer \& Hupfeld, 2004; Brewer, Potter, Fisher, Bond, \& Luszcz, 1999; Culhane \& Hosch, 2012). An investigator may choose to alter some details provided by the suspect by accident, or because they are convinced of the suspect's guilt, or in order to test a suspect's consistency. If these alterations are not detected by the suspect, innocent and guilty suspects may be considered inconsistent and therefore deceptive. As a consequence, investigators may become (even more) convinced of the suspect's guilt and increase their efforts to obtain a confession, regardless of the suspect's actual guilt or innocence (Kassin, Goldstein, \& Savitsky, 2003). As we know, the use of guiltpresumptive questions and exertion of pressure increases the risk of a false confession (Kassin et al., 2010). Likewise, jurors may come to the same conclusion during trial when presented with the inconsistencies in the suspect's testimony, while being unaware of the alterations introduced by the investigator.

Turning to the caveats of the current study, we would like to point out that the current study only tested blindness for frequency indications and not complete, elaborate suspect reports. Future research might address the question whether blindness is also prevalent for more extensive crime-related statements, alibis, and details that are not directly related to the criminal act, such as chronology, time indications, and locations. Given the robustness of blindness phenomena, we anticipate that blindness would also occur for such alterations. In this context, it may also be interesting to investigate the effect of lying as a means of increasing cognitive load (Vrij, Fisher, Mann, \& Leal, 2006, 2008; Vrij et al., 2011) or as a consequence of source disruption when participants provide elaborated descriptions of fabricated events (Pickel, 2004; Polage, 2012). According to the source-monitoring framework, the availability of an elaborated event description in memory impedes the reliability on the source markers for establishing whether the account was based on internal or external sources (i.e., internal fabrication or a perceived event). In the current study, however, participants did not elaborate on their answers. Therefore, we had not expected effects of lying as such.

Another limitation of the study refers to the fact that our experimenters were not blind to the hypothesis that fabrication increases blindness (but were blind to the other hypothesis). As described in the preceding text, several measures were taken to avoid possible experimenter effects (Rosenthal, 1966, 2002). These included a testing protocol that allowed no degrees of freedom in terms of which items would be altered and that gave firm guidance as to the kinds of questions participants would be asked. Regardless, the effect of fabrication on blindness should be replicated with blind experimenters. Finally, we had to rely on participants' self-reports in the current study. While overreporting is possible in principle, it seems more plausible that participants would underreport because of embarrassment or reluctance to disclose. With most alterations being increased, it is possible that a small number of alterations might have diverted from the actual number of transgressions to a larger extent than intended (i.e., more than three scale points), while a somewhat larger number of alterations might have diverted from the actual number of transgressions to a smaller extent than intended. Possibly, this decreased the number of detections. Given the substantial blindness rates reported in this study, this does not challenge the general conclusions of this work.

In summary, the current study showed that a meaningful number of people are blind to alterations of self-reports concerning their past transgressions. Extending previous work, we identified two moderators of this effect: fabrication and transgression history. Linking this work to suspect interrogations, we raised concerns about the probative value of testimony obtained employing deceptive or misleading interrogation techniques. The findings suggest that such misleading techniques could affect innocent suspects as well as guilty ones.

\section{ACKNOWLEDGEMENTS}

The authors would like to thank Hanane Bittich, Selma Kemmerer, and Svenja Mehlkopf for their help in collecting the data. 


\section{REFERENCES}

Allison, M., Mathews, K. R., \& Michael, S. W. (2012). Alibi believability: The impact of salacious alibi activities. Social Behavior and Personality, 40, 605-612. DOI:10.2224/sbp.2012.40.4.605.

Berman, G. L., \& Cutler, B. L. (1996). Effects of inconsistencies in eyewitness testimony on mock-juror decision making. Journal of Applied Psychology, 81, 170-177. DOI:10.1037/0021-9010.81.2.170.

Brewer, N., \& Hupfeld, R. M. (2004). Effects of testimonial inconsistencies and witness group identity on mock-juror judgments. Journal of Applied Social Psychology, 34, 493-513. DOI:10.1111/j.1559-1816.2004.tb02558.x.

Brewer, N., Potter, R., Fisher, R. P., Bond, N., \& Luszcz, M. A. (1999). Beliefs and data on the relationship between consistency and accuracy of eyewitness testimony. Applied Cognitive Psychology, 13, 297-313. DOI:10.1002/(sici)1099-0720(199908)13:4<297::aid-acp578>3.3.co;2-j.

Christianson, S. A., Engelberg, E., \& Gustafson, A. (2007). Recognition of previous eyewitness testimony from an altered interrogation protocol: Potential effects of distortions. Psychology, Crime \& Law, 13, 583-589. DOI:10.1080/10683160601095230.

Culhane, S. E., \& Hosch, H. M. (2012). Changed alibis: Current law enforcement, future law enforcement and layperson reactions. Criminal Justice and Behavior, 39, 958-977. DOI:10.1177/0093854812438185.

Dodson, C. S., \& Schacter, D. L. (2001). "If I had said it I would have remembered it": Reducing false memories with a distinctiveness heuristic. Psychonomic Bulletin \& Review, 8, 155-161. DOI:10.3758/ BF03196152.

Hall, L., Johansson, P., \& Strandberg, T. (2012). Lifting the veil of morality: Choice blindness and attitude reversals on a self-transforming survey. PLoS ONE, 7, e45457. DOI:10.1371/journal.pone.0045457.

Hall, L., Johansson, P., Tärning, B., Sikström, S., \& Deutgen, T. (2010). Magic at the marketplace: Choice blindness for the taste of jam and the smell of tea. Cognition, 117, 54-61. DOI:10.1016/j.cognition.2010.06.010.

Hall, L., Strandberg, T., Pärnamets, P., Lind, A., Tärning, B., \& Johansson, P. (2013). How the polls can be both spot on and dead wrong: Using choice blindness to shift political attitudes and voter intentions. PLoS ONE, 8, e60554. DOI:10.1371/journal.pone.0060554.

Hanley, J. A., Negassa, A., Edwardes, M. D. d B., \& Forrester, J. E. (2003). Statistical analysis of correlated data using generalized estimating equations: An orientation. American Journal of Epidemiology, 157, 364-375. DOI:10.1093/aje/kwf215.

Janardhanan, A. (2013, November 24). Ex-CBI man altered Rajiv death accused's statement. The Times of India. Retrieved from http://timesofindia. indiatimes.com

Johansson, P., Hall, L., \& Sikström, S. (2008). From change blindness to choice blindness. Psychologia: An International Journal of Psychology in the Orient, 51, 142-155. DOI:10.2117/psysoc.2008.142.

Johansson, P., Hall, L., Sikström, S., \& Olsson, A. (2005). Failure to detect mismatches between intention and outcome in a simple decision task. Science, 310, 116-119. DOI:10.1126/science.1111709.

Johansson, P., Hall, L., Tärning, B., Sikström, S., \& Chater, N. (2013). Choice blindness and preference change: You will like this paper better if you (believe you) chose to read it!. Journal of Behavioral Decision Making, 27, 281-289. DOI:10.1002/bdm.1807.

Johnson, M. K., Hashtroudi, S., \& Lindsay, D. S. (1993). Source monitoring. Psychological Bulletin, 114, 3-28. DOI:10.1037//0033-2909.114.1.3.

Johnson, M. K., Raye, C. L., Foley, H. J., \& Foley, M. A. (1981). Cognitive operations and decision bias in reality monitoring. American Journal of Psychology, 94, 37-64. DOI:10.2307/1422342.

Kassin, S. M., Drizin, S. A., Grisso, T., Gudjonsson, G. H., Leo, R. A., \& Redlich, A. D. (2010). Police-induced confessions: Risk factors and recommendations. Law and Human Behavior, 34, 3-38. DOI:10.1007/ s10979-009-9188-6.

Kassin, S. M., Goldstein, C. C., \& Savitsky, K. (2003). Behavioral confirmation in the interrogation room: On the dangers of presuming guilt. Law and Human Behavior, 27, 187-203. DOI:10.1023/A:1022599230598.

LaBar, K. S., \& Cabeza, R. (2006). Cognitive neuroscience of emotional memory. Nature Reviews Neuroscience, 7, 54-64. DOI:10.1038/nrn1825.
McDonough, I. M., \& Gallo, D. A. (2008). Autobiographical elaboration reduces memory distortion: Cognitive operations and the distinctiveness heuristic. Journal of Experimental Psychology: Learning, Memory, and Cognition, 34, 1430-1445. DOI:10.1037/a0013013.

Merckelbach, H., Jelicic, M., \& Pieters, M. (2011a). Misinformation increases symptom reporting - A test-retest experiment. Journal of the Royal Society of Medicine, 2. DOI:10.1258/shorts.2011.011062.

Merckelbach, H., Jelicic, M., \& Pieters, M. (2011b). The residual effect of feigning: How intentional faking may evolve into a less conscious form of symptom reporting. Journal of Clinical and Experimental Neuropsychology, 33, 131-139. DOI:10.1080/13903395.2010.495055.

Odinot, G., Wolters, G., \& van Giezen, A. (2013). Accuracy, confidence and consistency in repeated recall of events. Psychology, Crime \& Law, 19, 629-642. DOI:10.1080/1068316x.2012.660152.

Oeberst, A. (2012). If anything else comes to mind ... better keep it to yourself? Delayed recall is discrediting: Unjustifiably. Law and Human Behavior, 36, 266-274. DOI:10.1037/h0093966.

Pickel, K. L. (2004). When a lie becomes the truth: The effects of selfgenerated misinformation on eyewitness memory. Memory, 12, 14-26. DOI:10.1080/09658210244000072.

Polage, D. C. (2012). Fabrication inflation increases as source monitoring ability decreases. Acta Psychologica, 139, 335-342. DOI:10.1016/j. actpsy.2011.12.007.

Ridolfi, K., \& Possley, M. (2010). Preventable error: A report on prosecutorial misconduct in California 1997-2009. Santa Clara, CA: Northern California Innocence Project Publications.

Roozendaal, B., \& McGaugh, J. L. (2011). Memory modulation. Behavioral Neuroscience, 125, 797-824. DOI:10.1037/a0026187.

Rosenthal, R. (1966). Experimenter effects in behaviour research. New York: Merideth Publishing Company.

Rosenthal, R. (2002). Covert communication in classrooms, clinics, courtrooms, and cubicles. American Psychologist, 57, 839-849. DOI:10.1037/ 0003-066X.57.11.839.

Sagana, A., Sauerland, M., \& Merckelbach, H. (2013). Witnesses' blindness for their own facial recognition decisions: A field study. Behavioral Sciences and the Law, 31, 624-636. DOI:10.1002/bsl.2082.

Sagana, A., Sauerland, M., \& Merckelbach, H. (2014). "This is the person you selected": Eyewitnesses' blindness for their own facial recognition decisions. Applied Cognitive Psychology, 28, 753-764. DOI:10.1002/acp.3062.

Sauerland, M., Sagana, A., \& Otgaar, H. (2013). Theoretical and legal issues related to choice blindness for voices. Legal and Criminological Psychology, 18, 371-381. DOI:10.1111/j.2044-8333.2012.02049.x.

Sauerland, M., Sagana, A., Otgaar, H., \& Broers, N. J. (2014). Self-relevance does not moderate choice blindness in adolescents and children. PLOS ONE, 9, e98563. DOI:10.1371/journal.pone.0098563.

Sauerland, M., Sagana, A., Siegmann, K., Merckelbach, H., \& Jenkins, R. (2014). These two are different. Yes, they're the same: Choice blindness for facial identity. Manuscript submitted for publication.

Sauerland, M., Schell, J., Collaris, J., Reimer, N., Schneider, M., \& Merckelbach, H. (2013). "Yes, I have sometimes stolen bikes": Blindness for norm-violating behaviors and implications for suspect interrogations. Behavioral Sciences and the Law, 31, 239-255. DOI:10.1002/bsl.2063.

Smeets, T., Candel, I., \& Merckelbach, H. (2004). Accuracy, completeness, and consistency of emotional memories. American Journal of Psychology, 117, 595-609. DOI:10.2307/4148994.

Van Bergen, S., Horselenberg, R., Merckelbach, H., Jelicic, M., \& Beckers, R. (2010). Memory distrust and acceptance of misinformation. Applied Cognitive Psychology, 24, 885-896. DOI:10.1002/acp.1595.

Vrij, A., Fisher, R., Mann, S., \& Leal, S. (2006). Detecting deception by manipulating cognitive load. Trends in Cognitive Science, 10, 141-142. DOI:10.1016/j.tics.2006.02.003.

Vrij, A., Fisher, R., Mann, S., \& Leal, S. (2008). A cognitive load approach to lie detection. Journal of Investigative Psychology and Offender Profiling, 5, 39-43. DOI:10.1002/jip.82.

Vrij, A., Granhag, P. A., Mann, S., \& Leal, S. (2011). Outsmarting the liars: Toward a cognitive lie detection approach. Current Directions in Psychological Science, 20, 28-32. DOI:10.1177/0963721410391245. 